\title{
Research on injury prevention: time for an international agenda?
}

\author{
David H Stone
}

\begin{abstract}
Objective - To propose an initial agenda for a systematic international research strategy designed to meet the information needs of injury prevention worldwide. Criteria for inclusion and exclusion of articles - The world literature since 1977 was surveyed to obtain an overview of the current research effort on injury epidemiology and prevention. Articles were cited to illustrate the breadth and nature of work published on the topic with special reference to the prevention of home and traffic injuries.

Conclusions - There has been a recent upsurge of interest in injury prevention, although much of the work has been descriptive rather than analytical or evaluative. The implementation of existing knowledge has been patchy. To meet the information needs of effective injury prevention, several elements of an international research agenda are proposed. These include: the achievement of a consensus on terminology, definition, and classification; clarification of the roles of social deprivation, gender, risk taking behaviour, personality, stress, alcohol, drugs, chronic illness, and disability in the aetiology of injury; the development of multi-agency models of good injury prevention practice; the evaluation of counter-measures; the development and evaluation of routine injury surveillance systems.
\end{abstract}

\section{( $\mathcal{F}$ Epidemiol Community Health 1996;50:127-130)}

The prevention of injury is now widely accepted as a central objective of public health policy. Despite a large number of published reports on the causes, consequences, and prevention of injuries, the effective control of the current pandemic of trauma seems as elusive as ever. Research into the topic to date has been fragmented and uncoordinated. This duplication of effort, inefficient use of limited resources, and lack of effective communication between professionals mirrors similar shortcomings in the response of statutory services. A systematic international research strategy is required to meet the information needs of public health practitioners and other professionals and agencies charged with responsiblity for injury prevention. The purpose of this paper is to propose an initial agenda for such a strategy.

\section{Epidemiology of injury}

Injury is a global public health problem. The stark epidemiological facts are impressive. Each year, trauma results in around three million deaths and accounts for a third of all hospital admissions worldwide. ${ }^{1}$ In most countries, injury is the leading cause of death and is a major contributor to disability and health care expenditure. In the United States, there are around 140000 deaths and 2.3 million admissions to hospital because of injury each year. ${ }^{2}$ The total costs of injury to the American economy were estimated at $\$ 158$ billion in $1985 .^{3}$

In the United Kingdom, injuries cause about 12000 deaths each year, or two thirds of all deaths in healthy people. All age groups are affected; the greatest proportion of all deaths due to injury occurs in children and young adults but the absolute number of deaths is greatest in the elderly. The UK has one of the lowest overall injury death rates in Europe, although mortality from pedestrian injuries, especially in children, is higher than in most other European countries. In older age groups, a downward trend in mortality from injuries seems to have occurred in the last decade or so. ${ }^{4}$ Suicide is an exception and shows signs of a recent increase, especially in young men, in both Britain and in other parts of the world. ${ }^{5}$

Injuries lead to about half a million hospital admissions ( $8 \%$ of the total) in the UK each year and about seven million attendances (almost half the total) at accident and emergency departments. ${ }^{6}$ An unknown but undoubtedly large number of injured people are treated by community health services or do not present to any agency. There are few data on the long term effects of injuries and the disability associated with them with the arguable exception of road accidents involving head injury.

The main causes of injury in industrialised countries are accidents on the road, in the home, and during leisure or sporting activity. The relative contributions of these causes vary according to severity of outcome ${ }^{8}$ and age group. While road accidents contribute the 
largest proportion of deaths, home accidents contribute the largest proportion of hospital admissions. In Britain, home and road accidents together account for three quarters of injury deaths and $40 \%$ of cases attending accident and emergency departments.

Children and the elderly are most at risk from injuries sustained in the home. The epidemiological data on home injuries are scant because, as Pless ${ }^{9}$ points out, relatively few of these events are fatal. Preschool children are at particular risk, partly because of their greater exposure and partly because of their rapidly progressing physical and mental development.

Road traffic accidents are the major cause of accidental death in children under 15 and in young adults. ${ }^{24}$ Of the 300000 injury accidents per year in Great Britain reported through the police, about $80 \%$ are "slight", $18 \%$ "serious", and under $2 \%$ fatal. ${ }^{10}$ Fatal and serious casualty rates are generally higher in Scotland than in England and Wales, particularly in the case of child pedestrians. ${ }^{11}$

The risk of injury is strongly correlated with social disadvantage. There seems to be a stronger social class gradient in injury rates in fatal than in non-fatal injuries, but there have been fewer published studies on injury morbidity than mortality. ${ }^{12}$ Other risk factors include being male, alcohol intoxication, drug abuse, availability of firearms, and a range of environmental hazards.

A striking feature in the published reports is the consistency between studies in the basic epidemiological characteristics of the major categories of injuries, notwithstanding a degree of local variation. The occurrence of injuries is clearly not random but predictable in accordance with the known vulnerability of specific population subgroups. Nevertheless, there persists a fairly widespread attitude that most injuries are "accidental" and therefore unavoidable. This has led many professionals working in the field to call for the abandonment of the term "accident" with its fatalistic connotations in favour of the less ambiguous "injury". ${ }^{13-15}$ An international consensus on this point is unlikely to emerge for some time.

\section{National responses to the challenge of injuries}

Most injury preventive activities are sporadic, inconsistently applied, and uncoordinated. The pace-setter in recent years has been the United States. In 1985, the National Research Council of the National Academy of Sciences, in collaboration with the Institute of Medicine and the Committee on Trauma Research, released a seminal report Injury in America: $A$ Continuing Public Health Problem ${ }^{16}$ which called for increased spending on injury research and prevention. Congress responded promptly and injected $\$ 32$ million into an initial three year programme coordinated by the Centers for Disease Control. Since then, further central resources have been secured to consolidate and develop the programme. The CDC initiative has revitalised injury control efforts throughout the United States, both at national and state levels, and has attracted admiring attention in injury prevention circles far beyond its shores.

Canada, Australia, New Zealand, and the Scandinavian countries have all adopted vigorous injury control measures. The only remotely comparable attempt in the United Kingdom to place the subject on the national public health agenda was The Health of the Nation white paper ${ }^{17}$ which (along with equivalent policy statements for Scotland and Wales) identified five key areas one of which was accidents. One of the first steps taken to implement the new strategy was the establishment of a national Accidents Task Force with a remit which included identifying research and information needs. ${ }^{4}$

These developments present injury researchers with an unprecendented opportunity to influence public policy. Two implicit questions are enshrined in The Health of the Nation and similar policy documents elsewhere, and both need to be answered urgently. What is the role of research in promoting safety, and where are the major gaps in knowledge?

\section{International responses to the challenge of injuries}

The World Health Organization provides numerous opportunities for transnational cooperation through its "Health For All", "Healthy Cities", "Safe Communities", and "Cycle Helmet" initiatives. These are important mechanisms for exchanging information and for raising awareness but they also offer a framework for instituting international studies which few researchers have exploited.

The signing of the Treaty of European Union at Maastricht in 1993 has greatly enhanced the opportunities for European wide injury prevention activities by the inclusion of Article 129 which calls for the launching of public health initiatives while adhering to the principle of subsidiarity. In the course of a seminar on the public health implications of Maastricht sponsored by the European Commission and coordinated by the University of Birmingham's Health Services Management Centre, a working group on accidents and injuries emphasised the key role of adequate injury surveillance in informing the development of effective injury prevention policies.

While international collaboration on injury research has been remarkably weak to date, there are several notable exceptions. One is the European Commission demonstration project known as the European home and leisure accident surveillance system in which a network of national and local injury surveillance systems pool data and attempt to achieve a degree of standardisation in injury definitions, classifications and tabulations. ${ }^{18} \mathrm{~A}$ second is a World Health Organization supported international study of adolescent risk behaviour which is currently in progress.

Two other international programmes are worthy of specific mention. The United States National Centre for Health Statistics has held a number of methodological workshops to dis- 
cuss injury statistics under the auspices of an International Collaborative Effort (ICE), the impact of which remains unclear at the time of writing. ${ }^{19}$ And the BIOMED 2 research programme of the European Commission has for the first time explicitly included public health within its remit, reflecting Article 129 of the Maastricht Treaty.

The holding of the first World Injury Control Conference in Stockholm in 1990 was undoubtedly a landmark event. It was followed by a second conference in Atlanta in 1993 which stimulated discussions on the need for an international alliance of child injury researchers and professionals. As a result, two major initiatives were taken: the founding of the International Society for Child and Adolescent Injury Prevention and the launching of that organisation's journal Injury Prevention under the editorship of Professor Barry Pless.

\section{Current status of research on injury prevention}

The research community as a whole has been slow to respond to the challenge posed by injuries for a variety of reasons, mainly related to the availability of resources. In the United States, expenditure on federally funded research on injuries amounted to only one-ninth of the budget of the National Cancer Institute in the early $1980 \mathrm{~s}$, despite more than double the number of years of life lost as a result of injury than as a result of cancer. ${ }^{20}$ There are signs that this imbalance is being slowly rectified.

Research on injuries and their prevention is not exclusively health oriented but is performed in a wide variety of settings including engineering, industry, government, architecture, urban planning, and the insurance industry. Cross fertilisation between disciplines is limited. The flurry of reviews of injury prevention research which have been published recently ${ }^{9122}$ doubtless reflects a general renewal of interest in the topic, which may in turn have been fuelled by a growing awareness of the epidemiology, costs, and potential avoidability of trauma. A detailed reiteration of the contents and conclusions of these reviews lies beyond the scope of this paper. A recurrent message to emerge from them, however, is that conventional health educational interventions are generally less effective in preventing injuries than environmental or legislative measures, although there is clearly a place for all three types of activity.

Although substantial gaps in knowledge remain, a formidable portfolio of research papers now exists to guide policy makers responsible for safety promotion and injury prevention. The implementation of existing knowledge has been patchy partly because of the negative influence of powerful vested interests ${ }^{20}$ and partly because of an apparent lack of political will. ${ }^{1314}$ It is possible that some, at least, of this resistance can be overcome by the more effective dissemination and presentation of research findings, in particular by emphasising the enormous economic costs, and hence po- tential savings, associated with injuries and their consequences. ${ }^{32324}$

One of the major obstacles to the widespread acceptance and application of the insights gained by researchers is the detachment - administrative and intellectual - of academic departments from service agencies and policy makers. To an extent, the maintenance of professional distance between researchers and practitioners is desirable and even essential for the development of a vigorous and independent academe. On the other hand, the public health research agenda cannot be divorced from reality; it should reflect perceived deficiencies in the knowledge base required to solve the pressing problems of the day. If researchers were more explicit and communicative about their contribution to that knowledge base, practitioners might be more likely to heed their findings and support future investigations.

\section{Towards an international agenda for research on injury prevention}

The case for an international dimension to our collective attempts to research injury prevention is not self evident. It rests on a number of propositions which will be familiar to most injury researchers, namely:

- There is an inherent resistance to the allocation of national or local resources to injury prevention generally, ${ }^{25}$ which may be more easily overcome by collective international efforts than by lobbying solely within individual countries and regions;

- Detailed geographical comparisons are necessary to investigate possible reasons for the striking variations between countries in injury incidence, causes, and outcomes;

- International agreement on standardising injury definitions, classification, and reporting would greatly facilitate the interpretation of geographical variations;

- Injury researchers should learn more rapidly from each other's successes and failures;

- The world population is becoming increasingly mobile and interdependent;

- Hazards to safety are no respecters of political boundaries;

- Multi-centre studies can help increase statistical power and, through replication, enhance the credibility of results.

- The creation of a global information superhighway offers unprecendented opportunities for academic collaboration and discourse.

A priority task for injury researchers worldwide is to develop a common language so that communication and collaboration is feasible. This means arriving at a broad consensus about definitions, classification, and coding systems, and the most appropriate methodological approaches. This can begin now, building on the International Collaborative Effort. The other elements of an international research strategy will evolve in response to an ongoing process of reflection, discussion, and debate.

The following suggestions are intended to stimulate debate on the possible elements of an 
Proposed components of an international agenda for research on injury prevention

\begin{tabular}{|c|c|c|}
\hline Public health task & Global research & Comparative research \\
\hline Epidemiology & $\begin{array}{l}\text { Terminology, definition, } \\
\text { classification } \\
\text { Risk factors: gender, deprivation, } \\
\text { behaviour stress, alcohol, drugs, } \\
\text { illness, disability } \\
\text { Case fatality, long term survival, } \\
\text { quality of life }\end{array}$ & $\begin{array}{l}\text { Geography of injury } \\
\text { Cultural, social, professional } \\
\text { influences on injury occurrence } \\
\text { and reporting } \\
\text { Determinants of good prognosis }\end{array}$ \\
\hline Prevention & $\begin{array}{l}\text { Development of Interventions } \\
\text { Multi-agency models } \\
\text { Targeting of at risk groups }\end{array}$ & $\begin{array}{l}\text { Range of national policies } \\
\text { Varying resource allocation } \\
\text { Patterns of trauma care }\end{array}$ \\
\hline Evaluation & $\begin{array}{l}\text { Effectiveness of specific } \\
\text { countermeasures and community- } \\
\text { wide initiatives } \\
\text { Global injury surveillance }\end{array}$ & $\begin{array}{l}\text { Varying success of injury control } \\
\text { policies } \\
\text { National and local injury } \\
\text { surveillance }\end{array}$ \\
\hline
\end{tabular}

international injury prevention research agenda to replace the present piecemeal, arbitrary, and uncoordinated approach. They have been identified in accordance with a single overriding criterion - that they meet the information needs of effective injury prevention. Those needs may be summarised as follows:

- To understand the epidemiology and natural history of injuries;

- To select appropriate preventive interventions;

- To evaluate the impact (including the economic consequences) of these interventions.

Specific priorities for research can be identified within this framework (see Table). Among the topics of pressing global concern are:

- How to achieve an international consensus on injury terminology, definition, and classification;

- Development and evaluation of multi-agency models of good practice, based on the application of existing knowledge, to promote and implement injury prevention policies locally;

- Development and evaluation of the most appropriate, practical, valid, acceptable, and useful systems of routine injury surveillance as a source of data for epidemiological, preventive and evaluational purposes.

In addition, comparative issues requiring to be addressed urgently include:

- Varying injury mortality and morbidity rates between countries;

- Apparently successful national injury prevention policies and their relevance to other countries;

- The relative merits of the wide range of national, regional, and local approaches to injury surveillance and research.

\section{What next?}

The first step is for the international injury research fraternity, perhaps under the aegis of the US Centers for Disease Control and
Prevention, to hammer out a consensus view on the desirable components of a common injury research strategy, starting with its nosological and methodological foundations. Once this has been achieved, the endorsement of international agencies, including the World Health Organization and the European Union, should be sought to ensure that member states are alerted to the existence of the strategy and the central role it can play, if adequately supported, in the acquisition of the knowledge necessary for the protection of their populations from avoidable injury hazards.

I am grateful to the Chief Scientist Office of the Scottish Home and Health Department who partially supported this work. The views expressed in the paper are not, however, necessarily those views expressed in the paper are not, however, necessarily those thank two anonymous reviewers for their constructive comments on an earlier draft of the paper.

1 World Health Organization. Manifesto for safe communities. Stockholm: Karolinska Institute; 1989

2 Robertson LS. Injury epidemiology. New York: Oxford University Press, 1992

3 Rice DP, MacKenzie EJ, Jones AS, et al. Cost of injury in the United States: a report to Congress. San Francisco: Institute for Health and Aging (University of California), 1989.

4 Department of Health. The health of the nation key area handbook - accidents. London: Department of Health, 1993.

5 Diekstra RFW. The epidemiology of suicide and parasuicide. Acta Psychiatr Scand 1993;371(suppl):9-20.

6 National Association of Health Authorities/Royal Society for the Prevention of Accidents. Action on accidents - the unique role of the health service. Birmingham: NAHA, 1990.

7 Research Institute for Consumer Affairs. Knocked down. A study of personal and family consequences of road accidents involving pedestrians and pedal cyclists. London: Consumer Association, 1980.

8 Walsh SS, Jarvis SN. Measuring the frequency of "severe" accidental injury in childhood. $f$ Epidemiol Community Health 1992;46:26-32.

9 Pless IB. The scientific basis of childhood injury prevention - a review of the medical literature. London: Child Accident Prevention Trust, 1993.

10 Department of Transport. Road accidents Great Britain 1990 (the casualty report). London: HMSO, 1991.

11 Scottish Development Department. "Must do better". A study of child pedestrian accidents and road crossing behaviour in Scotland. Edinburgh: Scottish Office, 1989. Report by MVA Consultancy.

12 Baker S, O'Neill B, Ginsburg M, Li G. The injury fact book 2nd Ed. New York: Oxford University Press, 1992.

13 Rivara FP. Epidemiology of childhood injuries. 1. Revie of current research and presentation of conceptual framework. Am $\mathcal{F}$ Dis Child 1982;136:399-405.

14 Pless IB. Accident prevention. BMF 1991;303:462-4.

15 Bijur PE. What's in a name? Comments on the use of the terms "accident" and "injury". Injury Prevention 1995;1: 9-11.

16 National Research Council. Injury in America: a continuing public health problem. Washington DC: National Academy public health pr.

17 Department of Health. The health of the nation - a strategy for health in England. London: HMSO, 1992

18 Rogmans WHJ, Mulder S. European home and leisure accident surveillance system: evaluation of activities undertaken in the frame of the EC-demonstration project. Amsterdam: Consumer Safety Unit, 1990 .

19 Proceedings of the International Collaborative Effort on Injury Statistics. Vol 1. Hyatsville, MD: National Center for Health Statistics, Centers for Disease Control and Prevention, 1995.

20 Baker SP, Teret SP, Daub EM. Injuries. In: Levine S, Lilienfeld A eds. Epidemiology and health policy. London: Tavistock Publications, 1987.

21 Towner E, Dowswell T, Jarvis S. Reducing childhood accidents. The effectiveness of health promotion interventions: a literature review. London: Health Education Authority, 1993.

22 Neview. London. Health Education Authority, a he Injury prevention: meeting the challenge. New York: Oxford Injury prevention: meeting

23 Child Accident Prevention Trust. The NHS and social costs of children's accidents. A pilot study. London: Child Accident of children's accidents. A pilot

24 Mun E. Economic costs of trauma, US, 1982. I Trauma Man 1984;24:237-44.

25 Petridou E. Injury prevention: an uphill battle. Injury Prevention 1995;1:8. 